\title{
CFD ANALYSIS OF DRY CASK NUCLEAR FUEL STORAGE
}

\author{
KUTIŠ Vladimír ${ }^{1}$, GÁLIK Gabriel ${ }^{1}$, PAULECH Jauraj ${ }^{1}$, \\ MURÍN Justín', GOGA Vladimír ${ }^{1}$ \\ ${ }^{1}$ STU - Slovak University of Technology in Bratislava, \\ Faculty of Electrical Engineering and Information Technology, \\ Institute of Automotive Mechatronics, \\ Department of Applied Mechanics and Mechatronics, \\ Ilkovicova 3, 81219 Bratislava, Slovak Republic \\ e-mail:vladimir.kutis@stuba.sk,gabriel.galik@stuba.sk, \\ juraj.paulech@stuba.sk,justin.murin@stuba.sk,vladimir.goga@stuba.sk
}

\begin{abstract}
The article describes the thermo-hydraulic analysis of a dry cask storage building that is used for the storage of depleted nuclear fuel to determine the viability of a buoyancy driven cooling system. The analysis is performed in the form of steady-state CFD simulations. The resulting temperature distributions are them evaluated based on required operation criteria.
\end{abstract}

KEYWORDS: Finite Volume, CFD, ANSYS CFX, Nuclear Engineering

\section{Introduction}

The dry cask storage building represents mid to long term solution for the storage of depleted nuclear fuel assemblies. Individual Fuel assemblies [1] of reactor VVER440 [2] are bundled in hermetically sealed steel containers (casks). These casks are stored in a concrete air channel, where their decay heat is cooled by buoyancy driven air flow. The steady-state fluid flow analysis models the buoyancy driven air flow through the channel and the conductive and radiative heat transfer within the simulated domain.

In the presented preliminary CFD analysis the casks are considered as simplified cylinders with an outer diameter of $1.8 \mathrm{~m}$ and a total height $4 \mathrm{~m}$. total of 27 casks are distributed within three rows in a chequered pattern with an axial distance of $3 \mathrm{~m}$. The effective stack height of the air channel is $22 \mathrm{~m}$.

\section{Geometry and discretization of storage}

The analysis of the steady-state flow requires a geometric model of the internal volume of the air channel and its finite element mesh [3,4]. The internal volume geometry of the dry storage with the individual casks together with the riser section is shown in Fig. 1. The modelled domain of the internal volume of the dry storage represents the studied area of interest. All geometrical dimensions of the internal volume were based on available documentation.

Fig. 1 shows the inlet and outlet surfaces, through which the flowing air enters and exits the modelled domain, respectively. This figure also shows the numbered index of individual casks, that is being referenced in the results section. 


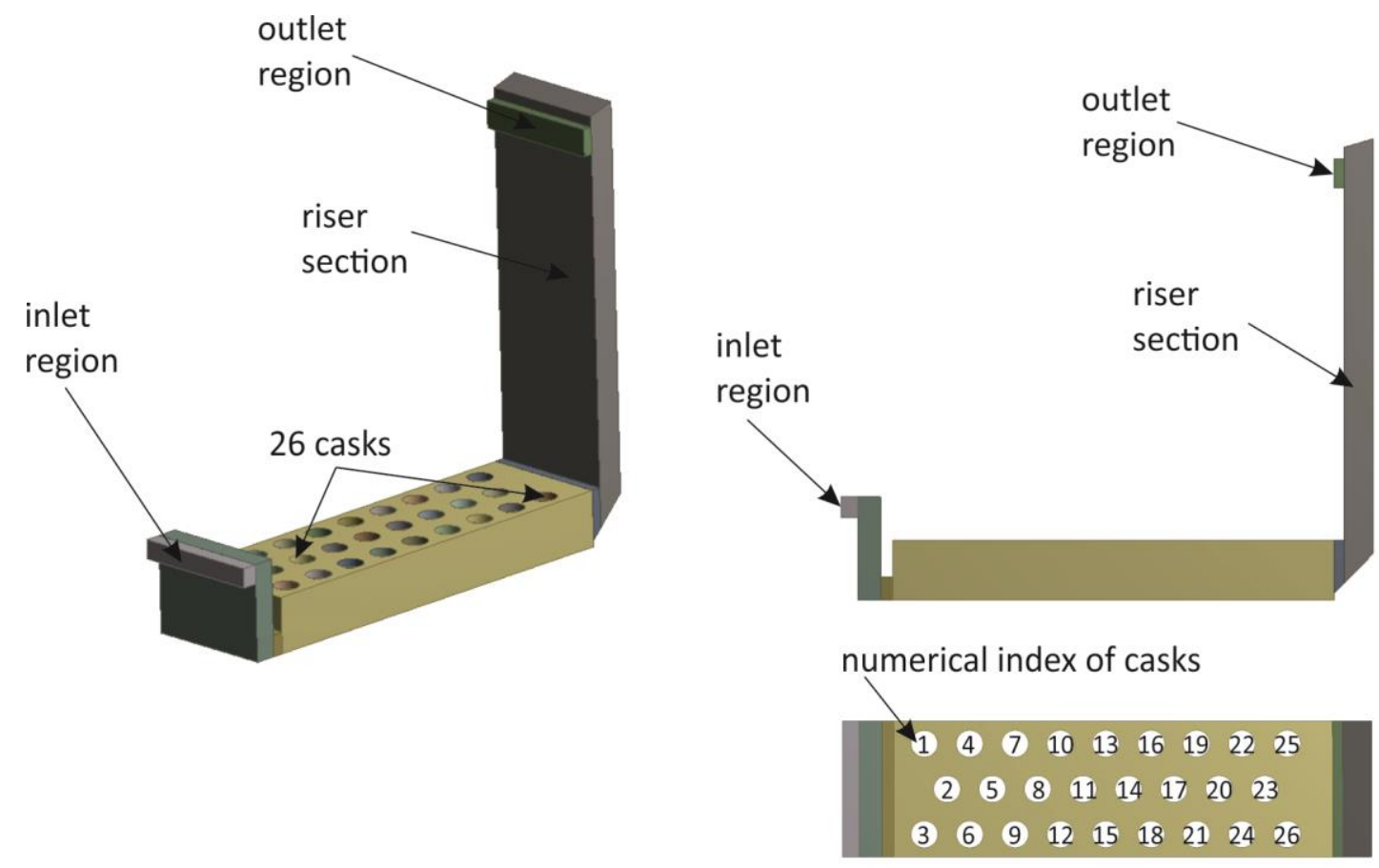

Fig. 1 Geometry of internal volume of the dry storage

The properties of the analysed case mean that the inlet and outlet boundaries have to be defined through a pressure condition. However, the pressure values depend on the boundaries differing vertical position and the flow velocity through the air channel. Therefore, the computational model had to be expanded by a volume of ambient air, which minimises the number of pressure boundary conditions, thereby reducing the numerical error caused by multiple pressure conditions [7]. The geometry of the dry storage together with the ambient volume is shown in Fig. 2.
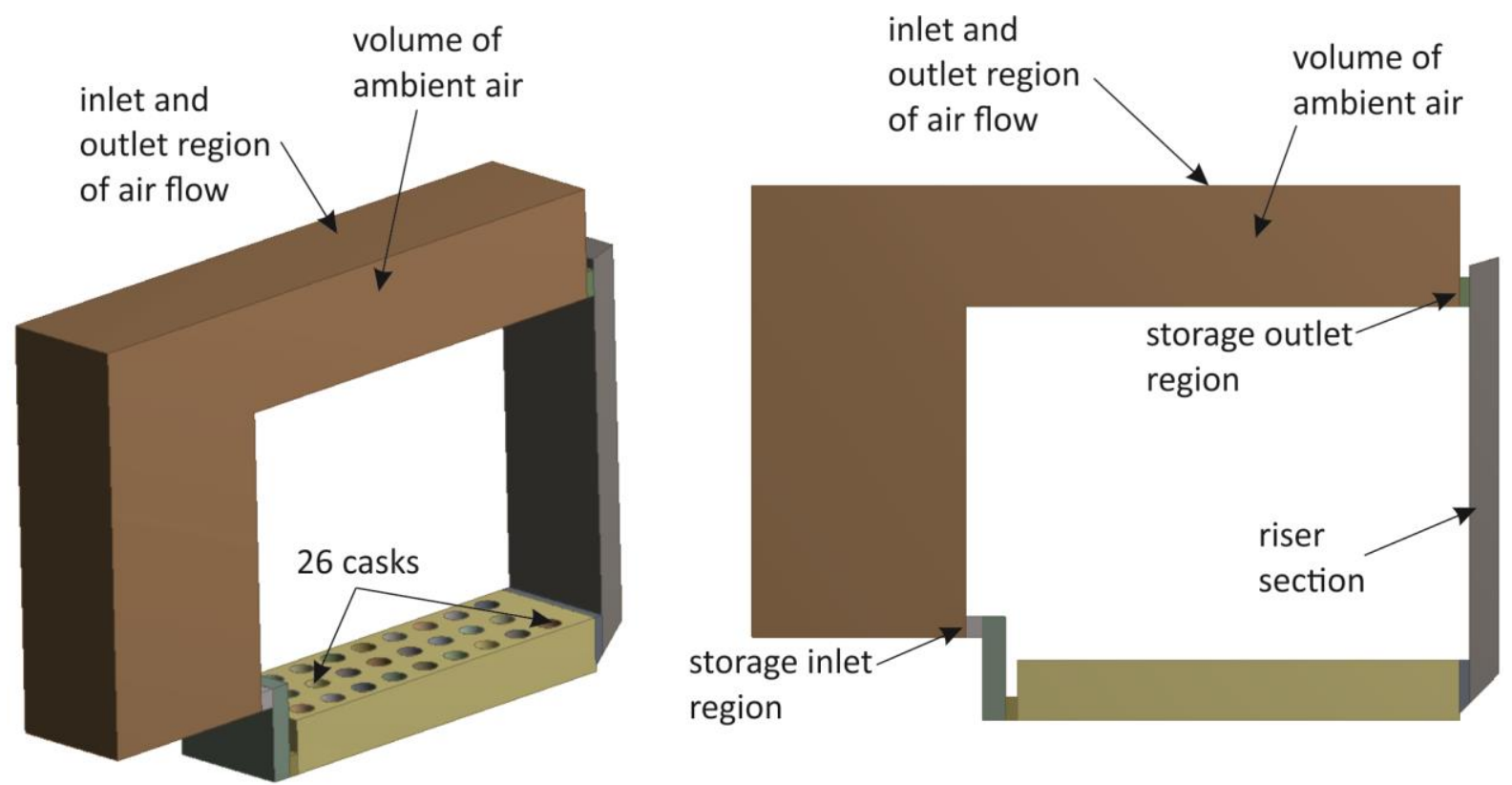

Fig. 2 Geometry of internal volume of the dry storage expanded with ambient air region 
Boundaries can be separated into the following groups based on near boundary flow characteristics:

- Opening boundary - the only boundary where air can enter and exit the modelled domain, Fig. 2 shows this boundary as "inlet and outlet region of airflow"

- Free slip wall - closed boundaries without forced boundary layers (all other boundaries of the ambient volume), these boundaries represent the borders of the modelled ambient air volume where no physical wall exists

- No slip wall - closed boundaries with forced boundary layers, represent physical wall surfaces (all remaining boundaries)

Model discretization was performed with ANSYS ICEM CFD. The whole finite element mesh created with blocking methodology with optimized mesh density and mesh quality parameters. Characteristics of the finished computational model:

- Mesh type: hexahedron

- Element number: 1490352

- Node number: 1705060

- First boundary layer thickness: $25 \mathrm{~mm}$

- Minimal determinant value: 0.48

- Minimal angle: $35.1^{\circ}$

- Maximal angle: $150.7^{\circ}$

Fig. 3 shows the computational mesh of the air channel. Fig. 4 shows the cross-section of the computational mesh within the air channel, between the individual casks.

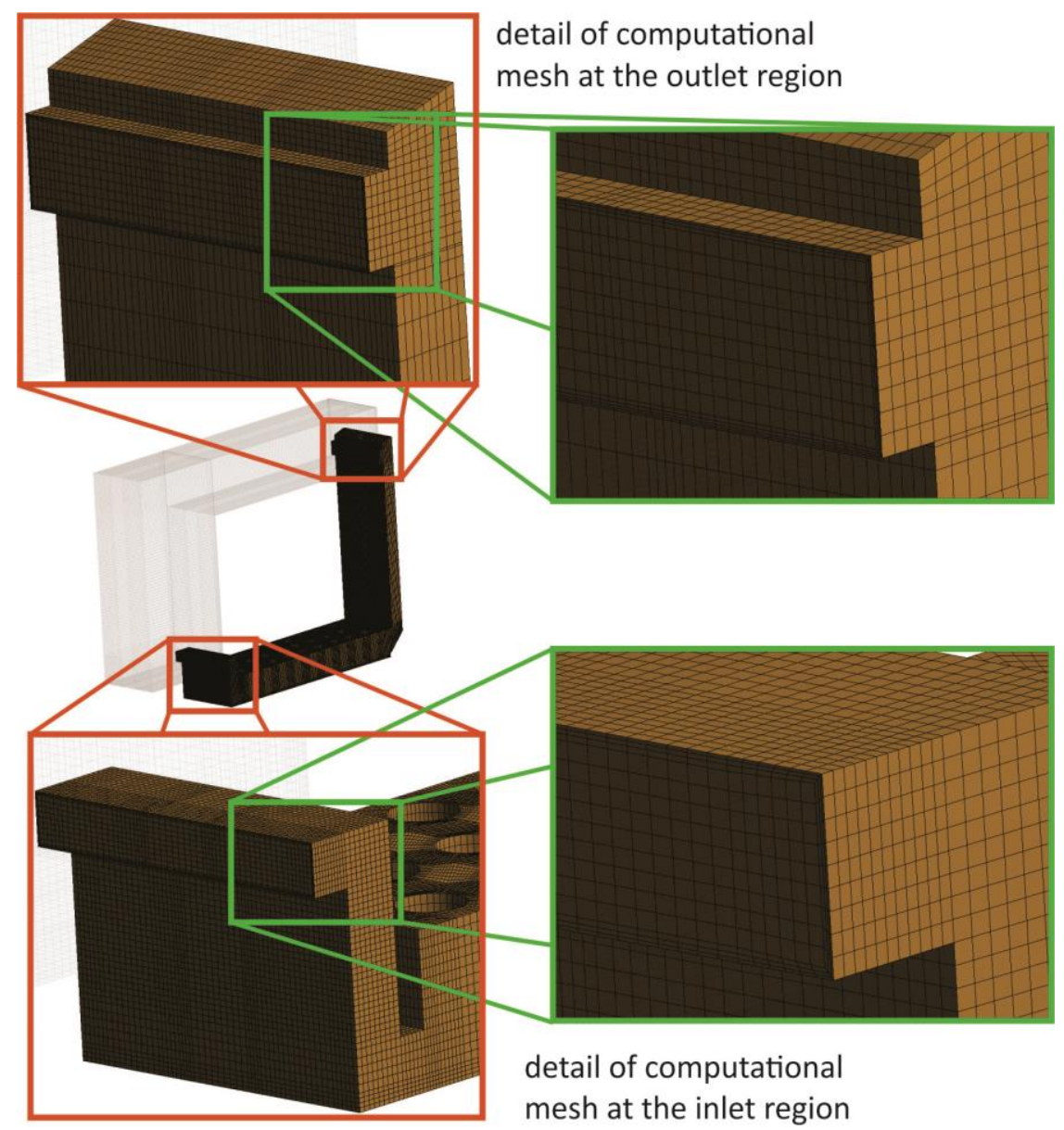

Fig. 3 Computational mesh of the internal air volume 


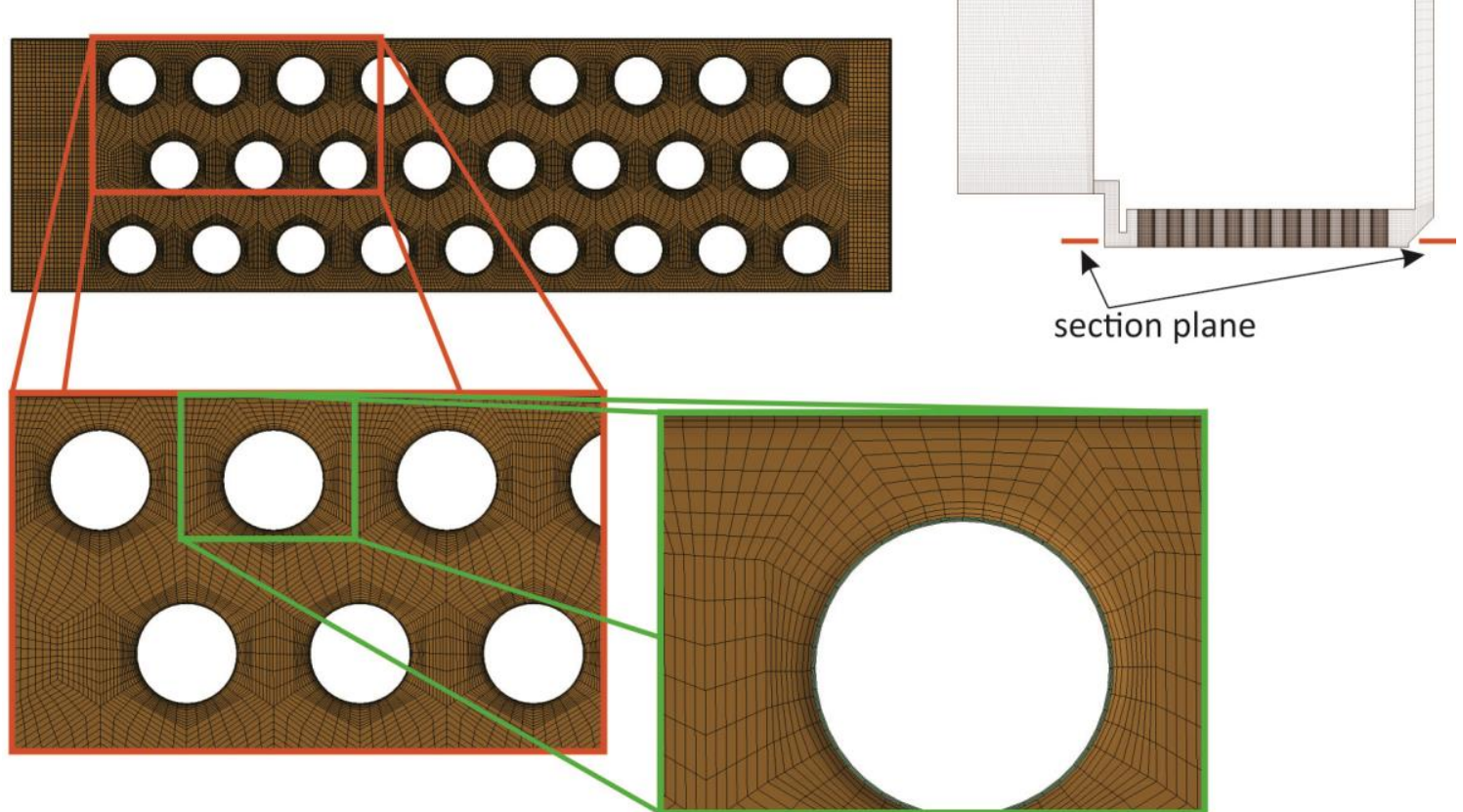

Fig. 4 Computational mesh in a horizontal cross-section

\section{Boundary conditions and loading}

Additionally to the computational model, the numerical simulation requires clearly defined boundary conditions and physical models [6]. Based on results from multiple sensitivity studies (these studies are beyond the scope of this article) the following setup was implemented for the analysis:

- Fluid material model: Air ideal gas

- Reference pressure: $101325 \mathrm{~Pa}(1 \mathrm{~atm})$

- Gravitational acceleration $\mathrm{g}=-9.81 \mathrm{~m} / \mathrm{s} 2$

- Turbulence model: SST

- Radiation model: Discrete transfer participating media

- Heat flux on cask surface: $17 \mathrm{~kW}$

- Air inlet temperature: $40{ }^{\circ} \mathrm{C}$

- Opening relative pressure: $0 \mathrm{~Pa}$

- Pressure drop on inlet and outlet grates: $10 \mathrm{~Pa}$

\section{$4 \quad$ Numerical simulations and obtained results}

Numerical simulation was performed on the computational model with the case described in the previous chapter. The parameter pressure drop on inlet and outlet grate was modelled using contact region properties and its value was defined as a function of mass flow. Acquired results for the given case were calculated and evaluated. The main parameters of the governing fluid flow are as follows:

- Air mass flow through the dry storage: $13.16 \mathrm{~kg} / \mathrm{s}$

- Air temperature at channel outlet: $73.08{ }^{\circ} \mathrm{C}$

- Maximum cask surface temperature: $196.43{ }^{\circ} \mathrm{C}$ 
Fig. 5 shows the distribution of temperature and wall heat transfer on the surface of individual casks. Fig. 6 shows the values of air flow velocities through the dry storage channel and the total air pressure in a plane positioned through the middle row of casks.

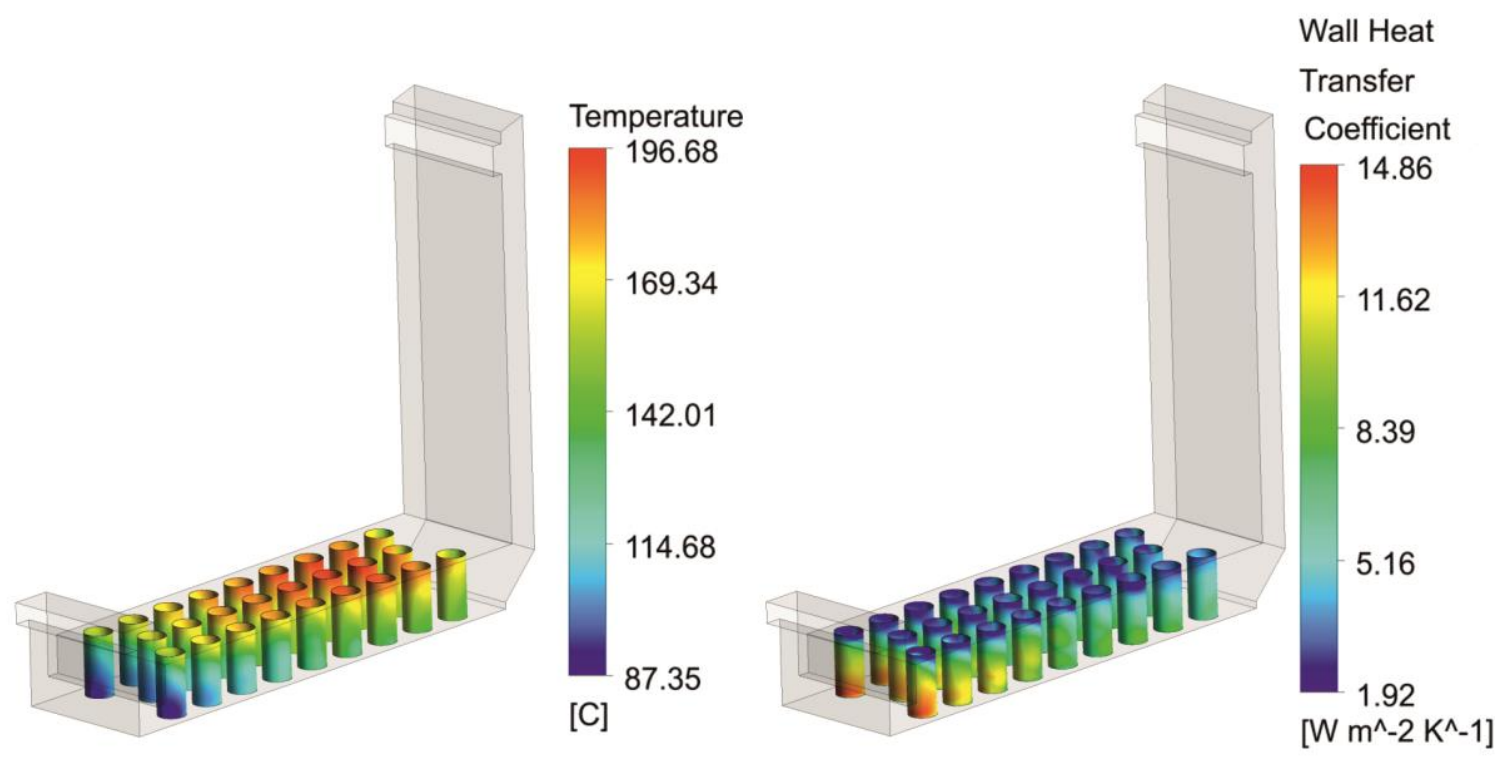

Fig. 5 Cask temperature and wall heat transfer coefficient distribution

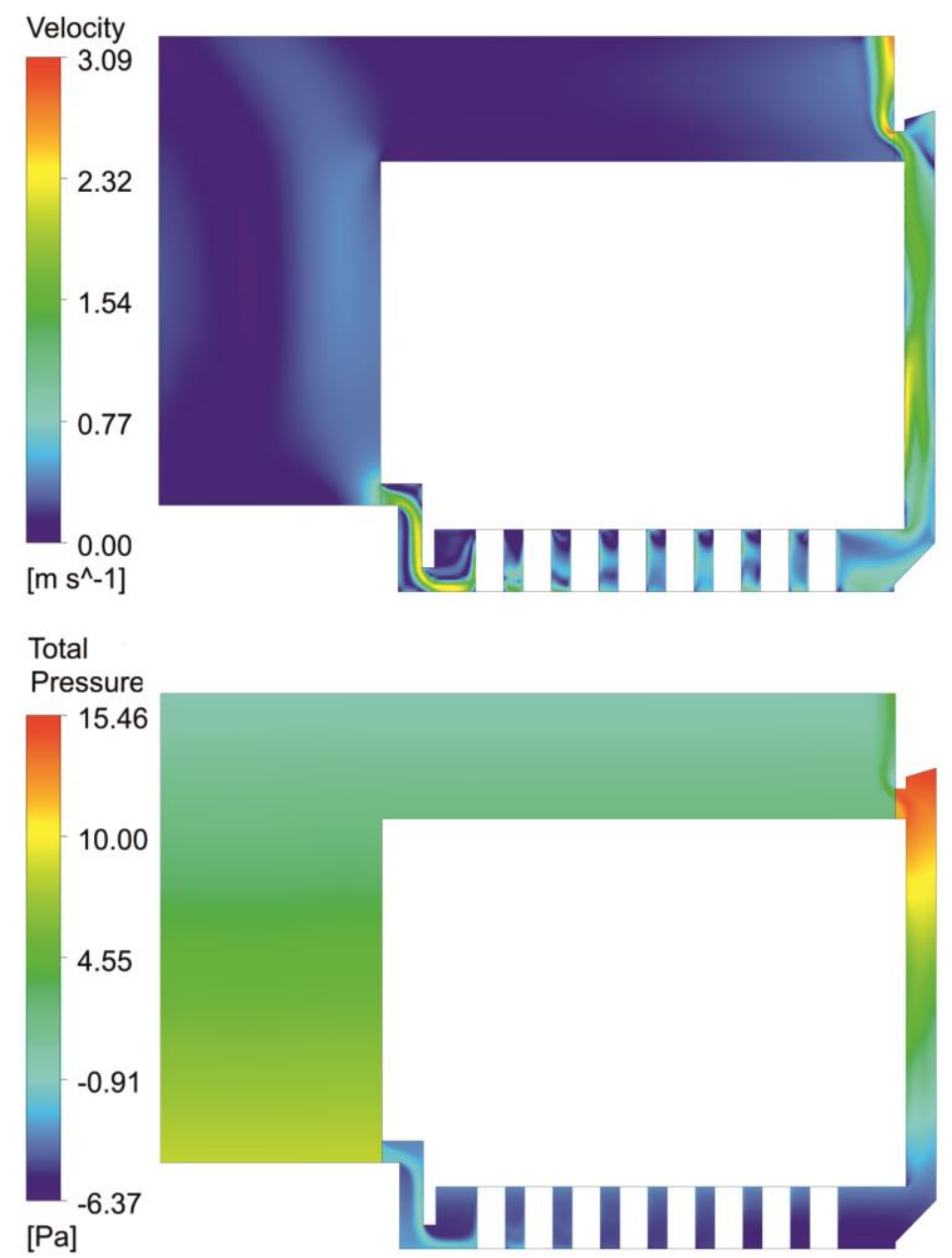

Fig. 6 Velocity field and relative pressure distribution on vertical mid plane cross-section 


\section{CONCLUSION}

As it is apparent from acquired results from the analysed case, air mass flow through the dry storage reaches $13 \mathrm{~kg} / \mathrm{s}$. Temperatures on the outer surfaces of casks for the analysed conditions and inlet outlet pressure drops can reach relatively high values. Based on these results, at the given conditions the dry storage channel's internal environment would not be suitable for manual operation.

\section{ACKNOWLEDGEMENTS}

This work was supported by the Slovak Grant Agency: VEGA No. 1/0081/18 and 1/0102/18, APVV-14-0613, APVV-0246-12. Authors are also grateful to the HPC Centre at the STU SIVVP project, ITMS code 26230120002.

\section{REFERENCES}

[1] Jakubec J., Paulech J., Kutiš V., Gálik G. "Influence Bypass on Thermo-Hydraulics of VVER440 Fuel Assembly", Strojnícky časopis - Journal of Mechanical Engineering 67 (1), pp. 69 - 76, 2017. DOI: 10.1515/scjme-2017-0007

[2] Kutiš, V., Jakubec, J., Paulech, J., Gálik, G., Sedlár, T. “CFD Analysis of Downcomer of Nuclear Reactor VVER 440”, Strojnícky časopis - Journal of Mechanical Engineering 66 (2), pp. 55 - 62, 2016. DOI: $10.1515 /$ scjme-2016-0018

[3] ANSYS Design Modeler, Manual, 2015.

[4] ANSYS ICEM CFD, Manual, 2015.

[5] ANSYS CFX, Theory Manual, 2015.

[6] Versteeg, H., Malalasekera, W. "An Introduction to Computational Fluid Dynamics: The Finite Volume Method", 2nd ed., Pearson Prentice Hall, London, England, 2007. ISBN 978-0-13-1274983.

[7] Source "Pressure drop online-calculator for mobile and PDA", [online] Available at: http://www.pressure-drop.mobi/ URL [Accessed: 1.2.2019]. 